\title{
On Managed Services Lanes and their Use in Home Networks
}

\author{
Frank den Hartog \\ TNO \\ P.O. Box 5050 \\ Erik Fledderus \\ TNO \\ P.O. Box 5050 \\ 2600 GB Delft, The Netherlands 2600 GB Delft, The Netherlands \\ Frank.denHartog@tno.nl \\ Erik.Fledderus@tno.nl \\ Pieter Nooren \\ TNO \\ P.O. Box 5050 \\ 2600 GB Delft, The Netherlands \\ Pieter.Nooren@tno.nl \\ Archi Delphinanto \\ TNO \\ P.O. Box 5050 \\ 2600 GB Delft, The Netherlands \\ Delphinanto@yahoo.com
}

\begin{abstract}
Home networks show an increasing level of

heterogeneity regarding the devices connected, network technologies used, and services supported. Heterogeneity inhibits quality assurance for new services, such as online gaming, energy management, and health care. This paper focuses on the role that the concept of Managed Services Lanes (MSLs) plays in Dutch smart-city initiatives to solve these issues. MSLs provide third-party service providers quality guarantees without infringing network neutrality. Our preliminary experiments with extending MSLs into the home network indicate that end users indeed have a better quality of experience for the supported Neighborhood TV service than without MSLs. We also show that extension of MSLs into the home network requires advanced home networking monitoring technologies including dynamic home network traffic models. Our research provides evidence that such models will be very different from the standard Internet models.
\end{abstract}

\section{Author Keywords}

Home networks; managed services lanes; smart cities; network monitoring

\section{ACM Classification Keywords}

C.2.3. Computer-communication networks: Network operations.
Copyright is held by the author/owner(s)

Zurich, Switzerland

ACM 978-1-4503-2139-6/13/09 \$15.00. 


\section{Introduction}

Western society faces a number of societal challenges, often referred to as 'Grand Challenges' [8]. The inevitable transitions and transformations that are required are becoming more and more manifest, especially in cities [2], and involving many different stakeholders. In the Netherlands, various smart-city projects are initiated where the operation of this ecosystem of stakeholders is tested with a variety of use cases. Well-known initiatives are the Amsterdam Smart City (ASC, http://amsterdamsmartcity.com) and AmersfoortBreed (Amersfoort Broadband, www.amersfoortbreed. $\mathrm{nl}$ ) projects. Internet technologies are expected to play a crucial role in these smart city projects. Social media, peer-to-peer networks, and other developments should enable cooperative community-based developments of digital services related to, for instance, mobility, local government, culture, sports, neighborhood safety and health, local energy management, online (serious) gaming, and community sensor networks.

Today's Internet is not designed to support the broad diversity of services required for smart cities and to be consumed in people's homes. Many services in the domains of health care, security, etc., need higher robustness and quality guarantees than can be delivered with the current unmanaged Internet and home network architectures. Furthermore, smart cities' network infrastructures will be significantly more heterogeneous than the current Internet, additionally frustrating the robustness and quality requirements. Also within the home network this increase in heterogeneity has been observed [9]. Networks from an increasing variety of domains need to be interconnected, such as utility networks, tele- communication networks, car networks, and hospital networks, whilst supporting end-to-end structural stability, open access, and quality of service (QoS).

This paper focuses on the interconnection of smart-city networks and home networks, and the role that the concept of Managed Services Lanes (MSLs) can play to solve the issues as described above. MSLs provide third-party service providers (SPs) quality guarantees without infringing network neutrality. We describe our experience with two smart-city experiments we have been involved with, both running in the Amsterdam Amersfoort region. The first one concerns a

Neighborhood TV pilot, which used the so far untested broadband access architecture including MSLs. The second experiment studies the requirements that MSLs put on home networks and home gateways.

\section{Managed Services Lanes}

Guaranteed-quality connections in triple play

Today, many broadband customers buy triple-play bundles which combine fast Internet, managed VoIP telephony and TV services in a single subscription. Although the services are part of a single commercial offering, they receive different technical treatment in the access network. In consumer subscriptions, the fast Internet service is a best-effort service, i.e. without guarantees on the quality of the connections.

Consequently, there are also no guarantees for the quality of the so-called Over-The-Top (OTT) services that are delivered over the Internet connection. The telephony and TV services, in contrast, are managed services designed to meet specific requirements for audio and video quality, and for service availability. This leads to the so-called two-lane model [10] for service delivery over broadband networks. OTT services 
and managed services are provided in parallel over a single broadband access connection. The quality of the managed services is guaranteed by, among other things, the use of bandwidth reservations in the access network. For instance, many Digital Subscriber Line (DSL) and fiber network operators use Ethernet Virtual LANs (VLANs) to partition and assign bandwidth to services. As a result, the IP traffic flows belonging to the managed services are separated from one another, and from the flows to and from the public Internet.

An important observation here is that in the triple play model described above, the guaranteed-quality connections that are created through the bandwidth reservations are typically only used for the network operator's own telephony and TV services. But guaranteed-quality connections could add value to important applications in other sectors as well, such as health, energy and security [11]. There is clearly an issue when this value is not realized, as there are large expectations for the contribution of broadband networks and services to solutions addressing the previously mentioned large societal challenges. Thus, the question arises as to whether it is useful to extend the use of guaranteed-quality connections to, for example, health and education services, which are currently delivered via either dedicated service-specific infrastructures or the best-effort public Internet. It is assumed that the broadband connection offers enough bandwidth to accommodate the additional guaranteedquality connections without substantially reducing the bandwidth available for public Internet access. Otherwise, the deterioration of the public Internet access is bound to raise net-neutrality-related concerns [12].
Demand-side requirements from non-triple play services

We have interviewed five Dutch SPs from non-telecom sectors about the services they plan to provide in the future using broadband networks. To goal was to gain better understanding of the demand for guaranteedquality connections for non-triple play services.

Through open questions, the providers were asked about existing services that are provided over the Public Switched Telephone Network today, such as a medical alert service, burglar and fire alarms, as well as services that they plan to provide in the future, such as remote examinations in education. They then assessed whether or not the current broadband networks meet the requirements for the delivery of these services. Table 1 shows their responses mapped to four requirement areas: bandwidth, quality, availability and security. The SPs were not obliged to cover all requirement areas in their answers.

Table 1 shows that both the downstream and upstream bandwidth available in Dutch broadband networks is not perceived as a limiting factor. This should be seen in the context of the Netherlands being one of the countries with the largest internet penetrations and average access speeds in the world, and may not be applicable to other countries. Other requirement areas show clear limitations, though:

- Quality: the quality of two-way voice and video is seen as insufficient for services in which close and uninterrupted communication is required.

- Availability: the down-time of connections because of network problems is seen as too large for services that are important in emergency situations. 


\begin{tabular}{|c|c|c|c|c|c|}
\hline $\begin{array}{l}n \\
\infty \\
\stackrel{2}{7} \\
\end{array}$ & Service & 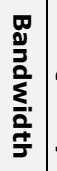 & 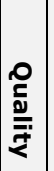 & 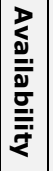 & 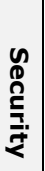 \\
\hline \multirow{3}{*}{$\begin{array}{l}\frac{I}{D} \\
\frac{\mathcal{N}}{F}\end{array}$} & $\begin{array}{l}\text { Medical alert } \\
\text { service: alert } \\
\text { emergency } \\
\text { response center by } \\
\text { pushing button }\end{array}$ & $\checkmark$ & $\checkmark$ & $x$ & \\
\hline & $\begin{array}{l}\text { Two-way video- } \\
\text { based smart living } \\
\text { services: extension } \\
\text { of medical alert } \\
\text { service with richer } \\
\text { communication }\end{array}$ & $\checkmark$ & $x$ & $x$ & \\
\hline & $\begin{array}{l}\text { Medical } \\
\text { monitoring: } \\
\text { remote monitoring } \\
\text { of weight, blood } \\
\text { pressure, body } \\
\text { temperature }\end{array}$ & $\checkmark$ & $\checkmark$ & $\checkmark$ & $?$ \\
\hline $\begin{array}{l}\frac{T}{\vec{D}} \\
\stackrel{\mathbb{D}}{1} \\
\stackrel{0}{2}\end{array}$ & $\begin{array}{l}\text { Smart meters: } \\
\text { remote measuring } \\
\text { of energy usage }\end{array}$ & $\checkmark$ & & $\checkmark$ & $x$ \\
\hline 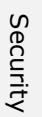 & $\begin{array}{l}\text { Burglar and fire } \\
\text { alarms }\end{array}$ & $\checkmark$ & & $x$ & \\
\hline \multirow{2}{*}{ 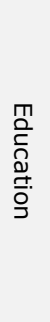 } & $\begin{array}{l}\text { Virtual class: } \\
\text { remote } \\
\text { participation in } \\
\text { classes through } \\
\text { two-way video }\end{array}$ & $\checkmark$ & $x$ & & \\
\hline & $\begin{array}{l}\text { Remote } \\
\text { examinations: take } \\
\text { official exams } \\
\text { through two-way } \\
\text { video }\end{array}$ & $\checkmark$ & $x$ & & \\
\hline
\end{tabular}

Table 1. How service providers assess the suitability of the current best-effort Internet for their services.
- Security: there are doubts as to whether public Internet connections are secure enough for services where protection and integrity of data are important.

The interviews thus point at other factors than bandwidth as inhibitors for new services. The security issues mentioned seem to be related to the application layer rather than the broadband infrastructure, and are therefore not further discussed in this paper. Quality and availability, on the other hand, can be directly related to properties of the network infrastructure. It is therefore worthwhile to investigate how broadband infrastructures can meet these requirements.

\section{Broker/VPN concept and operational implementation} Broker/VPN (Broker / Virtual Private Network) is a broadband network architecture developed and trialed by the Dutch network provider Reggefiber together with local communities and SPs. It is an implementation of the two-lane model, i.e. it provides guaranteed-quality connections for telephony and IPTV but also for other services that require more quality and reliability than offered by the public Internet. The first new service that uses the guaranteed-quality connections is a highquality Neighborhood TV service in the Dutch town of Zeewolde (see Figure 1). Through this service, live broadcasts of local events such as town council meetings, sport matches and theatrical performances are distributed to local community members.

In the Broker/VPN, Ethernet VLANs are used to separate the traffic flows of the best-effort public Internet access and the various managed services. Each VLAN is terminated on a separate Ethernet port on the Network Termination (NT) in the Home Gateway (HG). Depending on the customer's subscription, the total available bandwidth is typically 100 or $200 \mathrm{Mbit} / \mathrm{s}$, with 10 or $30 \mathrm{Mbit} / \mathrm{s}$ assigned to the Neighborhood TV service in VLAN no. 4. The Neighborhood TV service registers video signals and distributes them live to neighborhood viewers. The Broker/VPN connection is used for feeding the live video signal upstream, from the camera over the Fiber-to-the-Home network towards the IPTV platform. In the IPTV platform, the video feed is incorporated in the commercial set of IPTV channels and distributed downstream to the viewers using standard IPTV delivery protocols.

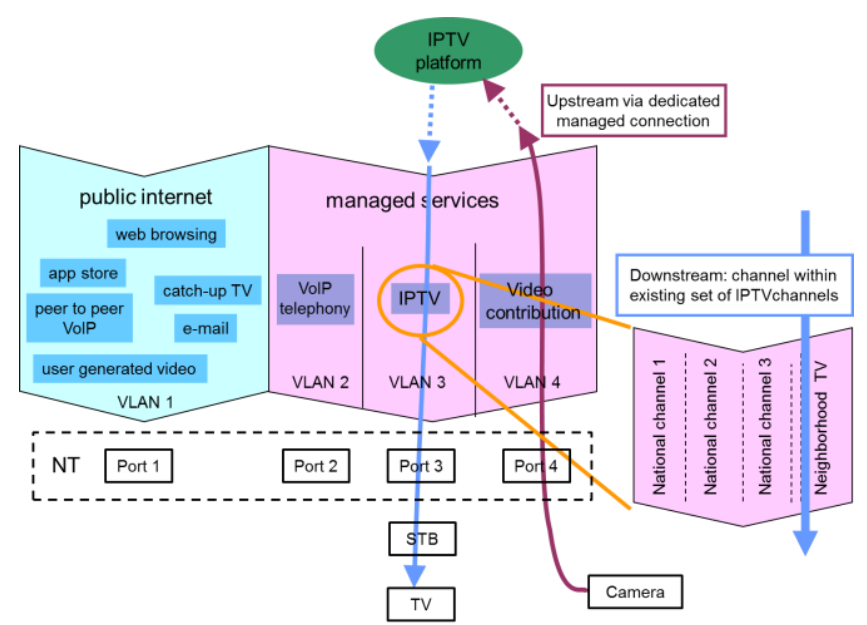

Figure 1: The delivery of managed IPTV services in Zeewolde including a 3rd-party Neighborhood TV channel, using a Broker/VPN managed connection.

Viewers of the Broker/VPN-supported Neighborhood TV service perceive the video quality as better, and in particular more stable, than in earlier implementations in which the upstream contribution occurred unmanaged over the public Internet. Future research at the network and video layers should confirm this result, 


\begin{tabular}{|ll|}
\hline Abbreviations \\
DSL & $\begin{array}{l}\text { Digital Subscriber } \\
\text { Line }\end{array}$ \\
DPI & $\begin{array}{l}\text { Deep Packet } \\
\text { Inspection }\end{array}$ \\
E2e & End-to-end \\
HG & Home Gateway \\
IP(TV) & Internet Protocol \\
& (TeleVision) \\
MSL & Managed Services \\
& Lanes \\
NT & Network Termination \\
OTT & Over The Top \\
QoS & Quality of Service \\
SP & Service Provider \\
SSID & Service Set IDentifier \\
STB & Set-Top Box \\
UPnP & Universal Plug and \\
& Play \\
V(LAN) & (Virtual) Local Area \\
\hline
\end{tabular}

and relate it to the relevant technical performance indicators. Also much appreciated by viewers is the ease of use that the Neighborhood TV service offers. Live video streams can be contributed to the IPTV platform from every fiber connection equipped with Broker/VPN, just by hooking up the camera to the specific Ethernet port on the NT. This also works in public buildings, such as the theater and the town hall, where upstreaming the video over the public Internet was often problematic because of various configuration issues in the private networks. These configuration problems are avoided in the Broker/VPN approach: if connected to the correct port, the camera does not have to be (auto-) configured locally by the HG first.

The VLAN used to implement the guaranteed-quality connection extends from the NT to a Point-of-Presence within the same city. This local VLAN is independent from other VLANs defined in the larger, national fiber network. Other local services may therefore share the VLAN for upstream video contribution, as long as they are offered by the same local SP. This SP has knowledge of the local services, and is therefore in a position to perform connection admission control to preserve the quality of these shared connections.

The administration of local VLANs is a substantial management effort for the operator. An alternative implementation therefore defines the VLANs in the national network, rather than locally within the smart cities. Such VLANs are especially attractive for SPS with a national customer base. At the same time, national VLANs require more coordination among the relevant SPs regarding connection admission control. This may lead to undesired dependencies between SPs.

\section{Smart City services support in the home}

Heterogeneity of home networks

In the Zeewolde pilot, the Broker/VPN VLAN is

terminated on a LAN port of the HG, and the camera must be connected to that port using a dedicated Ethernet cable. Only then, the bandwidth is reserved right down to the client device, and ease of use and end-to-end QoS can be guaranteed. This could also be done for other services using dedicated devices (e.g. burglar alarm systems, energy monitors, medical monitoring devices), using techniques like segmenting by IP address or using a different WiFi SSID. However, this configuration prevents the shared use of such devices by other services and devices in the home, especially if it concerns devices with more generic functionality, such as tablets. One can even argue that every device can in principle always be used for other services than the intentional one. Devices can only be shared if the home network is an integrated network.

Today, however, most home networks are unmanaged and lack QoS support. We do not expect this to change in the near future, as home networks are becoming increasingly heterogeneous. In such a context, the service's reliability and performance depend strongly on the characteristics of the home network [7]. They include static properties such as the topology, device characteristics, and the network technologies used, but also more dynamic properties such as individual session times and the utilization of the various links. The latter in particular is an issue for providers of managed highquality services such as IPTV and telephony [4], but also the services of Table 1.

The increasing heterogeneity has led to significant device- and service-management complexity [6]. As home networks are owned and controlled by the 


\section{Measurement setup}

In every household the local home gateway was replaced with a Linksys WRT54 GL v.1.0 broadband router and a monitoring laptop computer acting as a traffic recorder. The traffic recorder runs PRTG (wwww.peasler.com), which measures the rate of all incoming and outgoing traffic on every single port of the router at $10 \mathrm{~s}$ intervals. We observed incoming IP flows from the public Internet into the Local Area Network (LAN); outgoing traffic from LAN to the public Internet; and LAN-to-LAN traffic (which stays within the home). The router has five $100 \mathrm{mbit} / \mathrm{s}$ Ethernet ports and an IEEE $802.11 \mathrm{~g}$ access point acting as a single port. One Ethernet port was connected to the WAN, and another to our IP traffic recorder. On the other four ports, we measured and recorded the incoming traffic rate (in bit/s) for a full week. tenant, who is usually not an experienced network manager, it is often the helpdesk of the broadband access provider who gets called when a service malfunctions, even though he is not responsible for the home network. Such help desk calls are very expensive, because effective tools for remotely home network management hardly exist. Besides, home networks have also become increasingly personalized, meaning that (remote) troubleshooting and problem solving becomes more and more tailor-made work.

\section{Home network monitoring and modeling}

Forcing QoS in the home network with standard Diffserv-like techniques has proven to be impractical. These solutions need to be supported by every device in the end-to-end (e2e) path to be effective, which is a requirement that is hardly ever met in home networks. In the research project FIGARO (www.ict-figaro.eu), we take a different approach. We simply acknowledge the heterogeneity of the smart city network, especially it containing best-effort private networks such has home networks. Instead of trying to control the network across domains, we learn about all relevant network characteristics in real time and require the services and content to adapt accordingly. Service and content adaptation can be done in many ways, for instance by means of adaptive bitrate streaming, session admission control, or local caching. Although we realize that this is not an ideal solution, as it does not match the provided quality of the MSLs for $100 \%$, it is still better than besteffort, and for many services that will be enough.

The first step in this process is the development of intelligent home network monitoring tools. Available bandwidth monitoring tools [5] typically provide snapshots of the current state of the home network. To make decisions about content and service adaptation, also educated guesses should be made about the state of the home network in the near future. For that, models need to be developed describing the (statistical) home network behavior.

Standard Internet models cannot be adopted readily, because home networks have different characteristics. For example, one often assumes that the stochastic properties of traffic in the home network are the same as in the public Internet. However, there are many applications that run at home and congest the home network, but do not communicate with the public network. Examples are network printing, file transfer, content synchronization, internal control traffic (e.g. UPnP), and streaming media from a local storage device. To model these networks, we conducted a traffic measurement campaign in Amersfoort.

Results

So far, we have collected data in 15 selected households. We intend to triple this amount in the coming year, but our first results already look promising. The characteristics of the households are summarized in Table 2. Most participants can be classified as "early adopters", and we assume that prediction models resulting from these networks will be applicable to a much larger section of the total population in the near future. We also carried out a questionnaire-based survey to determine the Internet use profiles in our sample. The results are similar to what is known about the average Western population [3]. There are some minor differences, mainly in the use of audio/video services and terminal services (e.g. telnet), which indicated that our population is indeed significantly skewed towards early adopters. 


\begin{tabular}{|c|c|c|}
\hline & Type & \# \\
\hline House & $\begin{array}{l}\text { Terrace house } \\
\text { Apartments } \\
\text { Suburb house }\end{array}$ & $\begin{array}{l}9 \\
5 \\
1\end{array}$ \\
\hline $\begin{array}{l}\text { Network } \\
\text { type }\end{array}$ & $\begin{array}{l}\text { Access: Cable } \\
\text { Access: DSL } \\
\text { LAN: Ethernet+WiFi } \\
\text { LAN: Ethernet + Wifi } \\
\text { + Power line comm. }\end{array}$ & $\begin{array}{l}2 \\
13 \\
14 \\
1\end{array}$ \\
\hline $\begin{array}{l}\text { Av. \# of } \\
\text { network } \\
\text { ed } \\
\text { devices } \\
\text { per } \\
\text { house- } \\
\text { hold }\end{array}$ & $\begin{array}{l}\text { Laptop or PC } \\
\text { Multimedia Servers } \\
\text { Personal handheld } \\
\text { devices } \\
\text { Game Console } \\
\text { Others }\end{array}$ & $\begin{array}{l}4.6 \\
1.5 \\
1.2 \\
0.7 \\
1.0\end{array}$ \\
\hline User & $\begin{array}{l}\text { Families with children } \\
\text { Families without } \\
\text { children } \\
\text { Average \# of users } \\
\text { per house } \\
\text { \# hours daily spent on } \\
\text { networked } \\
\text { applications }\end{array}$ & $\begin{array}{l}12 \\
3 \\
3\end{array}$ \\
\hline
\end{tabular}

Table 2. Profile of the households and home networks that participated in our study.
Per household $i$ and per unit of time (10 s) the incoming traffic is summed over the ports, yielding the aggregated home networking traffic $x(n)$ at time $n$.

Figure $2 \mathrm{a}$ depicts the obtained probability mass function $p m f(x)$. Traffic rates higher than $40 \mathrm{kbit} / \mathrm{s}$, up to $92 \mathrm{Mbit} / \mathrm{s}$, have also been observed, but with a relative frequency lower than 0.002 . Despite the large statistical noise, the home-network traffic-rate distribution differs significantly from that of the Internet, which generally follows a Gaussian function [13]. Our results are better approximated by a Generalized Pareto distribution, with a root mean square error of 0.0005 . This can be explained by the fact that the Internet is always active, and statistical multiplexing can be applied, while home networks tend to have long periods of relatively low activity and support fewer applications. This result is remarkable, and important for smart cities. We expect that smart city networks will contain a disproportionally large amount of small private sub-networks like home networks, and must therefore most likely be modeled differently from the mainstream Internet.

We also studied the individual traces $x(t)$ for every $i$, and looked for sudden steps in $|x(t)|$ larger than $250 \mathrm{kbit} / \mathrm{s}$. The time between two such steps we call the application session time $d . p m f(d)$ is depicted in Figure $2 \mathrm{~b}$. The resulting curve can again be approximated with a Generalized Pareto distribution function, and an average application session time of about $500 \mathrm{~s}$. This value is surprisingly consistent with the average user session time reported by [1]

Apparently, content and service optimization systems in smart city networks can learn specifics about use patterns of best-effort private networks by monitoring

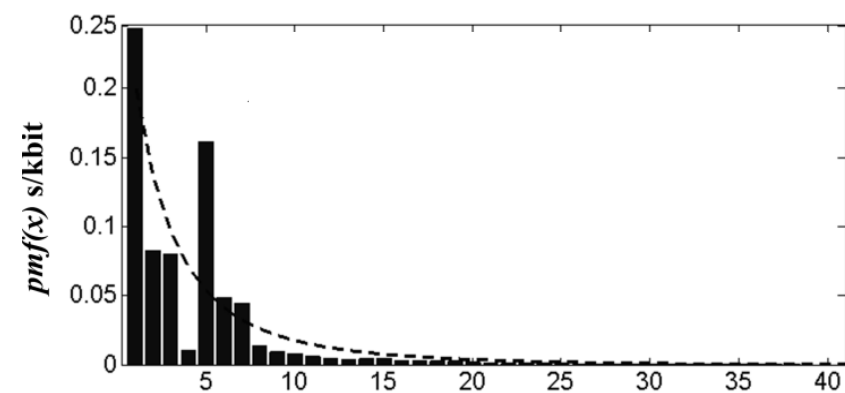

a)

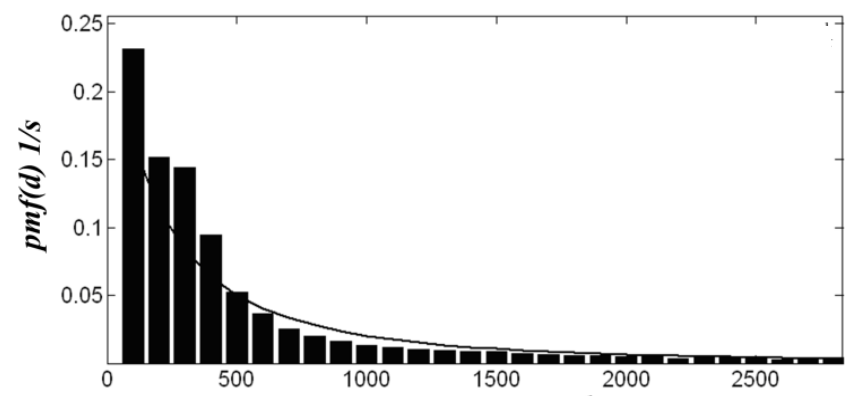

b)

Application session time, $d$ (in second)

Figure 2: a) The probability mass function of our observed aggregated home-network traffic rates $x, b)$ The probability mass function of the approximated application session time $d$.

traffic at the IP level, without first performing privacysensitive research by means of questionnaires or DPI.

\section{Conclusions}

Network heterogeneity inhibits service quality assurance considerably, especially when considering the high demands for robustness that new services require. Our survey results indicate that overdimensioning the public network's bandwidth is not the solution. The focus should rather be on improving the networks in a way that increases the quality and availability of the respective services. 
One way to do so is by introducing MSLs. The first results of our experiments with MSLs are promising. Network-neutrality concerns can be avoided as long as the MSLs do not influence the openness and the bandwidth of the public Internet services negatively. The MSLs cannot be extended into the home networks, but are terminated on the home gateway. For quality assurances in the home network we therefore propose the use of advanced network monitoring tools in combination with service and content adaptation. Such tools do not yet exist widely, and require the use of dynamic home network traffic models. From measurements in various homes we conclude that the amount of home network traffic as well as the observed application session times follow Generalized Pareto distributions. As a consequence, smart city networks cannot be understood with standard Internet models.

\section{Acknowledgements}

We thank Patrick Beitsma, Jouko Huismans, Jan Wester, Alwin Sixma, Freek Bomhof, and Robin Purchase for valuable input. This work was partly supported by the European Commission under the $7^{\text {th }}$ Framework Program, Grant Agreement 258378.

\section{References}

[1] Balachandran, A., Voelker, G. M., Bahl, G. P., and Rangan, P. Characterizing user behavior and network performance in a public wireless LAN, SIGMETRICS Perform. Eval. Rev. 30, 1 (2002), 195-205.

[2] Caragliu, A., Del Bo, C., and Nijkamp, P. Smart cities in Europe, J. Urban Tech. 18, 2 (2011), 65-82.

[3] Cheeseman Day, J., Janus, A., and Davis, J. Computer and Internet Use in the United States: 2003, U.S. Department of Commerce, Economics and Statistics Administration, U.S. CENSUS BUREAU, 2005.
[4] Delphinanto, A., Hillen, B.A.G., Passchier, I., van Schoonhoven, B.H.A., and den Hartog, F.T.H. Remote discovery and management of end-user devices in heterogeneous private networks, In Proc. of IEEE CCNC 2009, IEEE Press (2009).

[5] Delphinanto, A., Koonen, A. M. J., and den Hartog, F. T. H. Real-time probing of available bandwidth in home networks, IEEE Commun. Mag. 49, 6 (2011), 134-140.

[6] Develder, C. et al. Delivering Scalable Video with QoS to the Home, Telecommun. Syst. 49, 1 (2010), 129-148.

[7] DiCioccio, L., Teixeira, R., and Rosenberg, C. Impact of home networks on end-to-end performance: controlled experiments, In Proc. of HomeNets 2010 (ACM SIGCOMM workshop), ACM Press (2010).

[8] ETP Expert Group, Strengthening the role of European Technology Platforms in addressing Europe's Grand Societal Challenges, EUR 24196 EN, Publications Office of the European Union, Luxembourg, 2010.

[9] Loeb, H.P., Liss, C., Ruckert, U., Sauer, C. UMAC A Universal MAC architecture for heterogeneous home networks, In Proc. ICUMT '09, IEEE Press (2009), 1-6.

[10] Marcus, J.S., et al. Network Neutrality: Challenges and Responses in the EU and in the US, European Parliament, IP/A/IMCO/ST/2011-02, PE457.369, 2010.

[11] Middleton, C. Delivering services over next generation broadband networks: Exploring devices, applications and networks, Telecommunications Journal of Australia, vol. 60, no.4, pp. 59.1 (2010).

[12] Nooren, P., et al. "Net neutrality and the value chain for video," info 14, 6 (2012), 45-58.

[13] Pras, A., van de Nieuwenhuis, L., van de Meent, R. and Mandjes, M. Dimensioning network links: A new look at equivalent bandwidth, IEEE Network 23, 2 (2009), 5-10. 